\title{
Kinetic and Conventional Spectrophotometric Determination of Bumadizone in its Tablets via Oxidative Coupling with 3-Methyl-2- Benzothiazolinone Hydrazone
}

\author{
M. I. Walash, F. Belal, M. M. Tolba, M. I. Halawa* \\ Department of Analytical Chemistry, Faculty of Pharmacy, \\ University of Mansoura, 35516, Mansoura, Egypt. \\ mwalash@yahoo.com. \\ Department of Analytical Chemistry, Faculty of Pharmacy, \\ University of Mansoura , 35516, Mansoura, Egypt. \\ ffbelal@yahoo.com. \\ Department of Analytical Chemistry, Faculty of Pharmacy, \\ University of Mansoura, 35516, Mansoura, Egypt. \\ manar2kareem@yahoo.com. \\ Department of Analytical Chemistry, Faculty of Pharmacy, \\ University of Mansoura, 35516, Mansoura, Egypt. \\ m_halawa88@hotmail.com.
}

\begin{abstract}
:
Two simple, sensitive and accurate spectrophotometric methods have been developed for the determination of bumadizone in bulk drug and its tablets. Both methods based on the oxidative coupling reaction with 3-methyl-2benzothiazolinone hydrazone hydrochloride (MBTH) and measuring the absorbance of the developed colors by direct or kinetic spectrophotometric method. Upon treatment of a mixture of the chromogenic reagent and drug with cerium (IV) ammonium sulfate (method I) or ferric chloride (method I), a red or violet color was developed immediately or after 30 minutes measurable at $557 \mathrm{~nm}$ for method I or II, respectively. The absorbance-concentration plots were rectilinear over the ranges of $1-10 \mu \mathrm{g} / \mathrm{mL}(r=0.9999)$ for method I and $2-16 \mu \mathrm{g} / \mathrm{mL}(r=0.9998)$ for method II. The detection limits were 0.15 and $0.27 \mu \mathrm{g} / \mathrm{mL}$ \& the quantitation limits were 0.46 and $0.84 \mu \mathrm{g} / \mathrm{mL}$ for methods I and II, respectively. Different experimental parameters affecting the development and stability of the reactions products were studied and optimized. The proposed methods were applied successfully to the determination of bumadizone in its tablets, and the results obtained were in good agreement with those obtained using a comparison method.
\end{abstract}

Key words: Bumadizone; MBTH, Kinetic; Oxidative coupling; Pharmaceutical analysis.

\section{Council for Innovative Research}

Peer Review Research Publishing System

Journal: Journal of Advances in Chemistry

Vol. 5, No. 1

editor@cirworld.com

www.cirworld.com, member.cirworld.com 


\section{Introduction:}

Bumadizone calcium semi-hydrate (BUM) is butylmalonic acid mono-(1,2 diphenylhydrazide) calcium semihydrate; (Fig. 1). It is used as a non-steroidal anti-inflammatory drug and has a peripheral analgesic effect [1]

Literature survey revealed that there are only three chromatographic methods for determination of BUM [2-4]. To the best of our knowledge ,no spectrophotometric method has been yet reported for the determination of BUM in its tablets and this initiated this study.

Compared to chromatography, spectrophotometry is considered more convenient technique because of its inherent simplicity, low cost and wide availability.

Moreover, kinetic based methods (method II) offer many advantages other conventional ones such as, elimination of interference likely to be introduced from colored or turbid samples. Also, they eliminate the interference of other active compounds present if they are resisting the chemical reaction conditions established for the proposed kinetic method [5-9].

3-Methyl-2-benzothiazolinone hydrazone hydrochloride (MBTH) has been frequently utilized for spectrophotometric determination of several pharmaceutical compounds such as propranolol [6], ethamsylate [7], benazepril [8] and 4-quinolone antibacterials [9].

\section{Experimental:}

\subsection{Apparatus:}

Schimadzu UV-1601 PC UV-Visible double beam spectrophotometer (Kyoto, Japan) with matched $1 \mathrm{~cm}$ pathlength quartz cells. It is equipped with a kinetic accessory and temperature control unit (TCC-240 A).

\section{Materials and reagents:}

All reagents and chemicals used throughout this work were of Analytical Reagent grade and distilled water was used throughout this work.

- $\quad$ Bumadizone calcium semi-hydrate was kindly provided by October Pharma S.A.E. Company ( $6^{\text {th }}$ October City, Egypt) with a purity of $99.87 \%$ as determined by the comparison method [4].

- Octomotol W tablets (batch \# B1830212), labeled to contain $110 \mathrm{mg}$ of bumadizone calcium semi-hydrate, product of October Pharma S.A.E. Company, $6^{\text {th }}$ October City, Egypt.

- $\quad$ 3- Methyl-2-benzothiazolinone hydrazone (MBTH) (Sigma, St. Louis, MO). $0.3 \%$ w/v acidic solution was prepared in $0.2 \mathrm{M} \mathrm{HCl}$, this solution should be freshly prepared.

- $\quad \mathrm{Ce}(\mathrm{IV})$ ammonium sulfate (Merck, Darmstadt, Germany). $0.5 \%$ w/v acidic solution was prepared in $5 \% \mathrm{H}_{2} \mathrm{SO}_{4}$ solution.

- $\quad$ Ferric chloride was obtained from (Merck, Darmstadt, Germany). $0.5 \%$ w/v acidic solution was prepared in $0.5 \%$ $\mathrm{HCl}$ solution.

- Hydrochloric acid and Sulphuric acid (Merck, Darmstadt, Germany).

\subsection{Standard solutions:}

A stock solution was prepared by dissolving $10.0 \mathrm{mg}$ BUM in $100 \mathrm{~mL}$ distilled water, and it was further diluted with the same solvent as appropriate. The standard solutions were stable for 7 days when kept in a refrigerator.

\subsection{Procedures:}

\subsubsection{General Recommended procedures:}

\section{1- Method I:}

Accurately measured aliquots of the stock solution were quantitively transferred into a series of $10 \mathrm{~mL}$ volumetric flasks, so that the final concentration is in the range of $1-10 \mu \mathrm{g} \mathrm{mL}^{-1}$. To each flask, $1.2 \mathrm{~mL}$ of $0.3 \% \mathrm{MBTH}$ solution followed by $1.8 \mathrm{~mL}$ of $0.5 \%$ cerium (IV) solution were added and mixed well. The solutions were completed to the mark with distilled water and the absorbance was measured directly at $557 \mathrm{~nm}$ against a reagent blank. The calibration curve was constructed by plotting absorbance against final concentration of BUM $(\mu \mathrm{g} / \mathrm{mL})$. Alternatively, the corresponding regression equation was derived.

\section{2- Method II:}

To a set of $10 \mathrm{~mL}$ volumetric flasks, aliquot volumes of the stock solution were quantitavely transferred to obtain final concentration of $2-16 \mu \mathrm{g} / \mathrm{mL}$. To each flask, $1.2 \mathrm{~mL} 0.3 \% \mathrm{MBTH}$ solution followed by $2.5 \mathrm{~mL} 0.5 \% \mathrm{FeCl} 3$ solution were added and the solutions were completed to the mark with distilled water and mixed well. The increase in the absorbance at $557 \mathrm{~nm}$ was scanned during 30 minutes against a reagent blank, prepared simultaneously. The order of reaction was obtained by plotting log reaction rate $(\Delta \mathrm{A} / \Delta \mathrm{t})$ over the specified time period versus concentration of the drug 
The calibration graph was constructed by plotting absorbance after 30 minutes against final concentration of BUM $(\mu \mathrm{g} / \mathrm{mL})$. Alternatively, the corresponding regression equation was derived.

\subsubsection{Procedure for tablets:}

Ten tablets were weighed and pulverized. A quantity of the powder equivalent to $10.0 \mathrm{mg}$ BUM was transferred into a small conical flask and extracted with $3 \times 30 \mathrm{~mL}$ of distilled water for both methods. The extract was filtered into a $100 \mathrm{~mL}$ volumetric flask. The conical flask was washed with a few $\mathrm{mLs}$ of water. The washings were passed into the same volumetric flask and completed to the volume with the same solvent. Aliquot volumes covering the working concentration range were transferred into $10 \mathrm{~mL}$ volumetric flasks and the procedures described under "General Recommended Procedures" were then performed. The nominal content of the tablets was determined either from the previously plotted calibration graphs or using the corresponding regression equations.

\section{Results and discussion:}

Under the described experimental conditions, BUM was found to react with MBTH in presence of $\mathrm{Ce}(\mathrm{IV})$ or $\mathrm{FeCl} 3$ producing red or violet colored species peaking at $557 \mathrm{~nm}$ for method I or II, respectively (Fig. 2).

In method I, It was found that the red color developed immediately and remained constant by time. However, the intensity of the produced color in method II increases with time and this fact was used as a basis for a useful kinetic method (Fig. 3).

\subsection{Study of the experimental conditions}

\subsubsection{Effect of concentration of MBTH:}

The influence of the concentration of MBTH was studied by adding various volumes of its solution to a fixed concentration of BUM. It was found that, maximum and constant absorbance values were obtained using $1.2 \pm 0.2 \mathrm{~mL}$ of $0.3 \% \mathrm{MBTH}$ in both methods (Fig. 4). In addition, using $0.2 \mathrm{M} \mathrm{HCl}$ as a solvent for $\mathrm{MBTH}$ gave the maximum stability of the produced colors.

\subsubsection{Effect of volume of $\mathrm{Ce}(\mathrm{IV}) \& \mathrm{FeCl}_{3}$ :}

The influence of $\mathrm{Ce}$ (IV) ammonium sulfate $(0.5 \%)$ on the reaction in method I was studied. It was found that increasing the volume of $\mathrm{Ce}$ (IV) solution resulted in a corresponding increase in the absorbance of the reaction product up to $1.8 \pm 0.2 \mathrm{~mL}$, after which a subsequent decrease in the absorbance value was observed. Therefore, $1.8 \pm 0.2 \mathrm{~mL}$ of 0.5 $\%$ of $\mathrm{Ce}$ (IV) solution was chosen as the optimum volume in method I (Fig. 5).

Similarly, the effect of volume of $0.5 \% \mathrm{FeCl} 3$ in method II was studied. Maximum absorbance intensity was obtained upon using $2.5 \pm 0.2 \mathrm{~mL}$ as shown in Figure 5 .

\subsubsection{Effect of oxidizing agents:}

Different oxidants were tried including; $\mathrm{H}_{2} \mathrm{O}_{2}, \mathrm{~K}_{2} \mathrm{~S}_{2} \mathrm{O}_{8}$, iron ammonium sulfate, $\mathrm{Ce}(\mathrm{IV})$ ammonium sulfate, and $\mathrm{FeCl}_{3}$. In the first three cases, preliminary studies showed that the reaction rate was very slow and heating was necessary for developing the color. In addition, incomplete oxidation was observed as revealed by very low absorbance values. So, $\mathrm{Ce}(\mathrm{IV})$ ammonium sulfate and $\mathrm{FeCl}_{3}$ were selected as the best oxidizing agents as they gave the highest absorbance values and more reproducible results.

\subsubsection{Effect of surfactants :}

The effect of different surfactants (cetrimide, gelatin, tween 80 and sodium dodecyl sulphate) on the color intensity at three different concentration levels $(2.5,7.5$ and $15 \mu \mathrm{g} / \mathrm{mL})$ was studied. All of the tested surfactants have a little diminishing effect on the absorbance in both methods (Table 1). This may be attributed to the partial consumption of the oxidant by the surfactants, and oxidation to products other than the active species.

\subsubsection{Effect of diluting solvent:}

The nature of diluting solvent is of significant importance in both methods. So, different solvents including; ethanol, methanol, DMF, DMSO, dichloromethane, acetonitrile, isopropanol, acetone and water were investigated. Acetonitrile was found to be the most appropriate solvent for method I. Ethanol and methanol were found to react with the tested oxidant as both could act as reducing agents and this resulted in development of highly unstable chromogen. Other solvents were not used due to turbidity, formation lower absorbance values and lower sensitivity compared to those obtained upon using water. Therefore, water was chosen as the best solvent allover the study in methods I and II because it gave the highest absorbance readings. Moreover, its availability and low cost added to its advanatages.

\subsubsection{Effect of time on development and stability of reaction products :}

In method I, The color intensity reached its maximum immediately and remained stable for along time. However, the absorbance of the reaction mixture in method II increased with time and never reach maximum in a reasonable time. Quantitation was therefore made at a fixed time of 30 minutes in method II (Fig. 3). 


\subsection{Evaluation of the Kinetic Method (Method II):}

Variable time measurement, rate-constant, fixed absorbance, and fixed time methods [10,12] were tried, and the most suitable analytical method was selected, taking into account the applicability, sensitivity, intercept, and correlation coefficient ( $r$ ).

\subsubsection{Variable time measurement:}

The rate of the reaction was found to be dependent on BUM concentration. The rates were followed at room temperature with various concentrations of the drug in the range of $2-16 \mu \mathrm{g} / \mathrm{mL}$ keeping the $\mathrm{MBTH}$ and Ce(IV) concentrations constant (Fig. 3). The reaction rate was found to obey the following equation:

$$
\text { Rate }=\mathrm{k}-[\mathrm{BUM}] \mathrm{n}
$$

Where $\mathrm{k}$ - is the pseudo-order rate constant and $\mathrm{n}$ is the order of the reaction. The rate of the reaction may be estimated by the variable-time measurement [12] as $\Delta \mathrm{A} / \Delta \mathrm{t}$, where $\mathrm{A}$ is the absorbance and $\mathrm{t}$ is the time in seconds. Taking logarithms of rates and concentrations (Table 2); the previous equation is transformed into:

$$
\log \Delta \mathrm{A} / \Delta \mathrm{t}=\log \mathrm{k}-+\mathrm{n} \log [\mathrm{BUM}]
$$

Regression of log (rate) versus log [BUM] gave the following regression equation:

$$
\text { Log rate }=0.38+0.80 \log C(r=0.9992)
$$

Hence k- $=2.41 \mathrm{~s}-1$, and the reaction is pseudo-first order $(n=0.8)$ with respect to BUM concentration $(C)$ and the rate will be directly proportional to drug concentration. Such dependence can be used for quantitative analytical purposes.

\subsubsection{Rate constant Method:}

Graphs of log absorbance versus time for BUM concentration in the range of $8.69 \times 10-6-2.32 \times 10-5 \mathrm{M}$ were plotted and all appeared to be rectilinear. Pseudo-first order rate constants (K') corresponding to different drug concentrations (C) were calculated from the slopes multiplied by -2.303 and are presented in Table (3). Regression of $(C)$ versus $\mathrm{K}^{\prime}$ gave the following equation:

$$
K^{\top}=7.0 \times 10-4+24.06 \mathrm{C}
$$

$$
(r=0.9863)
$$

\subsubsection{Fixed absorbance method:}

Reaction rates were recorded for different BUM concentrations in the range of $1.74 \times 10-5 \mathrm{M})$. A preselected value of the absorbance (0.3) was fixed, and the time was measured in seconds. The reciprocal of time (1/t) versus the initial concentration of BUM (Table 4) was plotted, and the following equation of the calibration graph was obtained:

$$
1 / \mathrm{t}=-3.0 \times 10-3+139.87 \mathrm{C} \quad(r=0.9992)
$$

\subsubsection{Fixed time method:}

Reaction rates were determined for different concentrations of BUM. At a preselected fixed time, which was accurately determined, the absorbance was measured. Calibration graphs of absorbance versus initial concentration of BUM were established at fixed times of $5,10,15,20,25,30$ and $35 \mathrm{~min}$, and the corresponding regression equations are assembled in Table (5). It is clear that, the slope increases with time and the most acceptable values of the correlation coefficient and the intercepts were obtained for a fixed time of $25 \mathrm{~min}$. which was therefore chosen as the most suitable time interval for measurement. After optimizing the reaction conditions, the fixed time method was applied for the determination of BUM in pure form over the range $2-16 \mu \mathrm{g} / \mathrm{mL}$.

\subsection{Validation of the methods:}

The proposed methods were tested for linearity, repeatability, intermediate precision, accuracy and robustness according to ICH Q2R1 recommendations [13].

\subsubsection{Linearity and range:}

After optimizing the reaction conditions, the calibration graph was rectilinear over the range of $1-10 \mu \mathrm{g} / \mathrm{mL}$ or 2$16 \mu \mathrm{g} / \mathrm{mL}$ for methods I or II, respectively. The linear regression analysis of the data gave the following equations:

$$
\begin{array}{ll}
A=4.20 \times 10-3+0.06 C & (r=0.9999) \rightarrow \text { For method I } \\
A=1.73 \times 10-3+0.06 C & (r=0.9998) \rightarrow \text { for method II }
\end{array}
$$

Where: $A$ is absorbance, $C$ is the concentration of the drug $(\mu \mathrm{g} / \mathrm{mL})$ and $r$ is regression coefficient.

Statistical evaluation [14] gave high values of the correlation coefficient $(r)$ of the regression equation, small values of the standard deviation of the residuals (Sy /x), of the intercept (Sa) and of the slope (Sb), and small values of the percentage relative standard deviation and the percentage relative standard error (Table 6). These data proved the linearity of the calibration graphs. 


\subsubsection{Limit of quantitation (LOQ) and limit of detection (LOD):}

(LOQ) and (LOD) were calculated according to ICH Q2R1 recommendations using the following equation [13] :

$$
\mathrm{LOQ}=10 \mathrm{~S}_{\mathrm{a}} / \mathrm{b} \quad \mathrm{LOD}=3.3 \mathrm{~S}_{\mathrm{a}} / \mathrm{b}
$$

Where: $S_{a}=$ the standard deviation of the intercept of the calibration curve and $b=$ slope of the calibration curve. The values of LOQ and LOD are abridged in Table 6.

\subsubsection{Accuracy and precision:}

To prove the accuracy of the proposed methods, the results of the assay of BUM were compared to the comparison method [4]. Statistical analysis of the results using the Student's $t$-test and the variance ratio F-test [14] revealed no significant difference in the performance of the two methods regarding accuracy and precision, respectively (Table 7). The comparison method [4] involved HPLC method using a mobile phase consisting of methanol - water acetonitrile (20:30:50), C18 column and UV detection at $235 \mathrm{~nm}$.

For both methods, intraday and interday precisions were assessed using three concentrations and three replicates of each concentration. The relative standard deviations were found to be very small indicating reasonable repeatability and intermediate precision of the proposed methods ( Table 8 ).

\subsubsection{Robustness:}

The robustness of the proposed methods was checked by studying the effect of small deliberate variations of some experimental conditions such as the change in the volume of $0.3 \% \mathrm{w} / \mathrm{v} \mathrm{MBTH}(1.2 \pm 0.2 \mathrm{~mL}), 0.5 \% \mathrm{w} / \mathrm{v} \mathrm{Ce}(\mathrm{IV})(1.8$ $\pm 0.2 \mathrm{~mL})$ and $0.5 \% \mathrm{w} / \mathrm{v} \mathrm{FeCl} 3(2.5 \pm 0.2 \mathrm{~mL})$. These minor changes that may take place during the experimental operation didn't affect the absorbance of the reactions products (Fig. 4,5 ). This indicated the reliability of the proposed methods during its routine application for the analysis of BUM.

\subsubsection{Selectivity:}

The selectivity of the methods was investigated by observing any interference encountered from common tablet excipients. It was found that these compounds didn't interfere with the results of the proposed methods(Table 9).

\subsection{Pharmaceutical applications:}

The proposed methods were successfully applied to the determination of BUM in commercial tablets. The results shown in Table 9 are in good agreement with those obtained using the comparison method [4]. Statistical analysis of the results using the Student's $t$-test and the variance ratio F-test [14] revealed no significant difference between the performance of the two methods regarding accuracy and precision, respectively.

\subsection{Mechanism of the reaction:}

The Stoichiometry of the reaction was studied adopting the limiting logarithmic method [15]. Plots of log absorbance versus log [MBTH] and log [BUM] gave two straight lines in method I as a model example. The slopes of these lines were 0.95: 0.97 for MBTH and BUM, respectively (Fig. 6). Hence, it was concluded that the reaction proceeds in the ratio of $1: 1$.

Based on the above fact and by analogy to previous reports [16], the proposed reaction pathway is postulated to proceed as shown in Scheme 1.

\section{Conclusion:}

The present study described for the first time, a successful analysis of BUM with simple spectrophotometric methods using MBTH as an analytical reagent. The proposed methods have many advantages; they don't need expensive sophisticated apparatus, simple, rapid, and sensitive.

Furthermore, they don't require elaboration of procedures, which are usually associated with chromatographic methods. The proposed methods could be applied successfully for determination of the studied compound in pure form as well as in its tablets. Therefore, the methods are practical and valuable for routine analysis of BUM in quality control laboratories. 
Table (1): Effect of surfactants.

\begin{tabular}{|c|c|c|c|}
\hline \multirow{2}{*}{ Surfactant } & \multirow{2}{*}{$\begin{array}{l}\text { Concentration } \\
\qquad \mu \mathrm{g} / \mathrm{mL}\end{array}$} & \multicolumn{2}{|c|}{ Absorbance } \\
\hline & & Method I & Method II \\
\hline No surfactant & 0 & 0.55 & 0.94 \\
\hline Cetrimide & 2.5 & 0.42 & 0.42 \\
\hline & 7.5 & 0.45 & 0.47 \\
\hline & 15 & 0.48 & 0.51 \\
\hline Sodium lauryl sulfate & 2.5 & 0.39 & 0.40 \\
\hline & 7.5 & 0.41 & 0.44 \\
\hline & 15 & 0.42 & 0.49 \\
\hline Gelatin & 2.5 & 0.44 & 0.51 \\
\hline & 7.5 & 0.47 & 0.56 \\
\hline & 15 & 0.51 & 0.61 \\
\hline Tween 80 & 2.5 & 0.32 & 0.50 \\
\hline & 7.5 & 0.36 & 0.53 \\
\hline & 15 & 0.40 & 0.60 \\
\hline
\end{tabular}

Table (2): Logarithms of rates for different concentrations of BUM at $557 \mathrm{~nm}$ at room temperature.

\begin{tabular}{|c|c|}
\hline $\operatorname{og} \Delta \mathrm{A}$ & -og [BUN \\
\hline-4.02 & -5.54 \\
\hline-3.75 & -5.23 \\
\hline-3.63 & -5.06 \\
\hline-3.46 & -4.84 \\
\hline-3.39 & -4.76 \\
\hline-3.30 & -4.64 \\
\hline
\end{tabular}


Table (3) : Values of $K$ calculated from slopes of $\log A$ vs time graphs at $557 \mathrm{~nm}$.

\begin{tabular}{|c||c|}
\hline $\mathrm{K}^{\prime}\left(\mathrm{s}^{-1}\right)$ & {$[\mathrm{BUM}]$} \\
\hline \hline $9.21 \times 10^{-4}$ & $8.69 \times 10^{-6}$ \\
& \\
\hline $10.50 \times 10^{-4}$ & $1.45 \times 10^{-5}$ \\
& \\
\hline $11.70 \times 10^{-4}$ & $1.74 \times 10^{-5}$ \\
& \\
\hline & \\
\hline
\end{tabular}

Table (4): Values of reciprocal of time taken at fixed absorbance for different rates of variable concentrations of BUM at constant concentrations of $\mathrm{MBTH}$ and $\mathrm{FeCl} 3$ at room temperature.

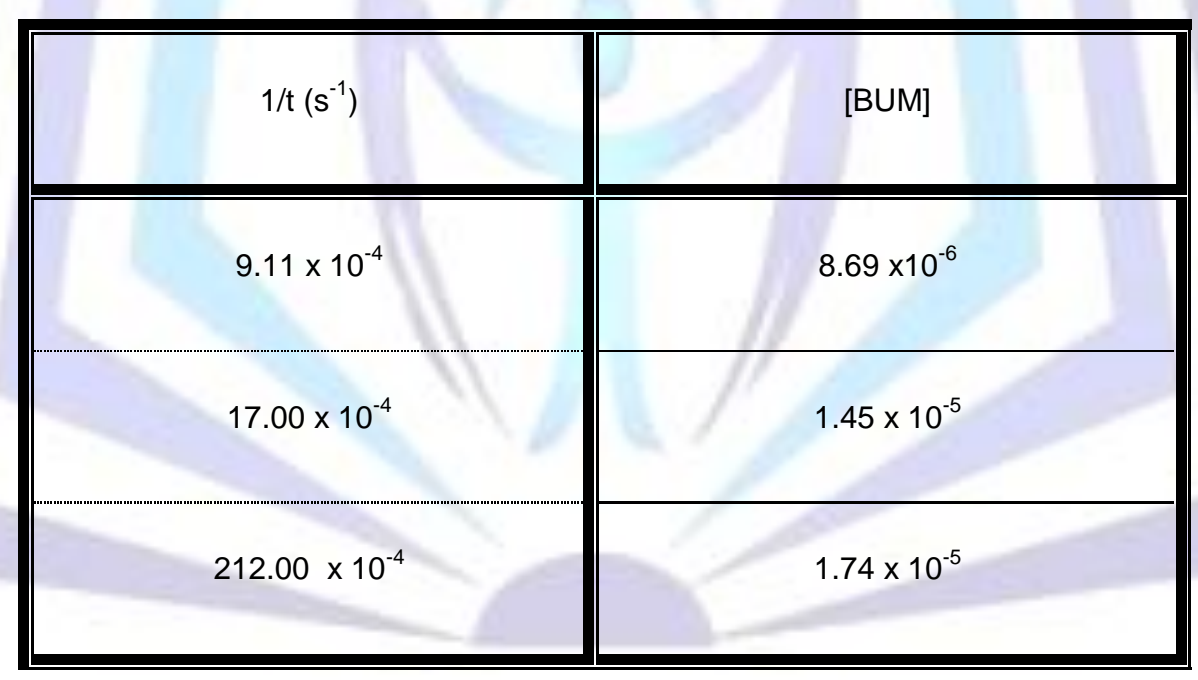


Table (5): Regression equations for BUM at different fixed time over the range of $(2.90 \times 10-6-2.32 \times$ 10-5 M).

\begin{tabular}{|c|c|c|}
\hline Time (min.) & Regression equation & Correlation coefficient $(r)$ \\
\hline 5 & $-5.00 \times 10^{-2}+0.02 C$ & 0.9936 \\
\hline 10 & $-2.50 \times 10^{-2}+0.03 \mathrm{C}$ & 0.9995 \\
\hline 15 & $-2.00 \times 10^{-2}+0.04 C$ & 0.9997 \\
\hline 20 & $1.65 \times 10^{-2}+0.05 \mathrm{C}$ & 0.9998 \\
\hline 25 & $1.31 \times 10^{-2}+0.06 \mathrm{C}$ & 0.9999 \\
\hline 30 & $1.92 \times 10^{-2}+0.06 \mathrm{C}$ & 0.9998 \\
\hline 35 & $2.23 \times 10-2+0.06 \mathrm{C}$ & 0.9997 \\
\hline
\end{tabular}

Table (6): Analytical performance data of the proposed methods.

\begin{tabular}{|l|c|c|}
\hline \multicolumn{1}{|c|}{ Parameter } & Method I & Method II \\
\hline Concentration range $(\mu \mathrm{g} / \mathrm{mL})$ & $1.0-10.0$ & $2.0-16.0$ \\
Limit of detection $(\mathrm{LOD})(\mu \mathrm{g} / \mathrm{mL})$ & 0.15 & 0.28 \\
Limit of quantification $(\mathrm{LOQ})(\mu \mathrm{g} / \mathrm{mL})$ & 0.47 & 0.84 \\
Correlation coefficient $(\mathrm{r})$ & 0.9999 & 0.9998 \\
Intercept $(\mathrm{a})$ & $4.20 \times 10^{-3}$ & $1.73 \times 10^{-2}$ \\
Slope (b) & $6.17 \times 10^{-2}$ & $5.83 \times 10^{-2}$ \\
S. D. of residuals $\left(\mathrm{S}_{\mathrm{y} / \mathrm{x})}\right.$ & $3.70 \times 10^{-3}$ & $6.00 \times 10^{-3}$ \\
S. D. of intercept $\left(\mathrm{S}_{\mathrm{a}}\right)$ & $2.90 \times 10^{-3}$ & $4.90 \times 10^{-3}$ \\
S. D. of slope $\left(\mathrm{S}_{\mathrm{b}}\right)$ & $5.00 \times 10^{-3}$ & $5.00 \times 10^{-3}$ \\
\hline
\end{tabular}


Percentage relative standard deviation, \% RSD

Percentage relative error, \% Error

Molar absorpitivity $(\xi) \quad\left(\right.$ L.mol $\left.{ }^{-1} \cdot \mathrm{cm}^{-1}\right)$

Table (7): Application of the proposed and comparison methods to the determination of bumadizone in pure form.

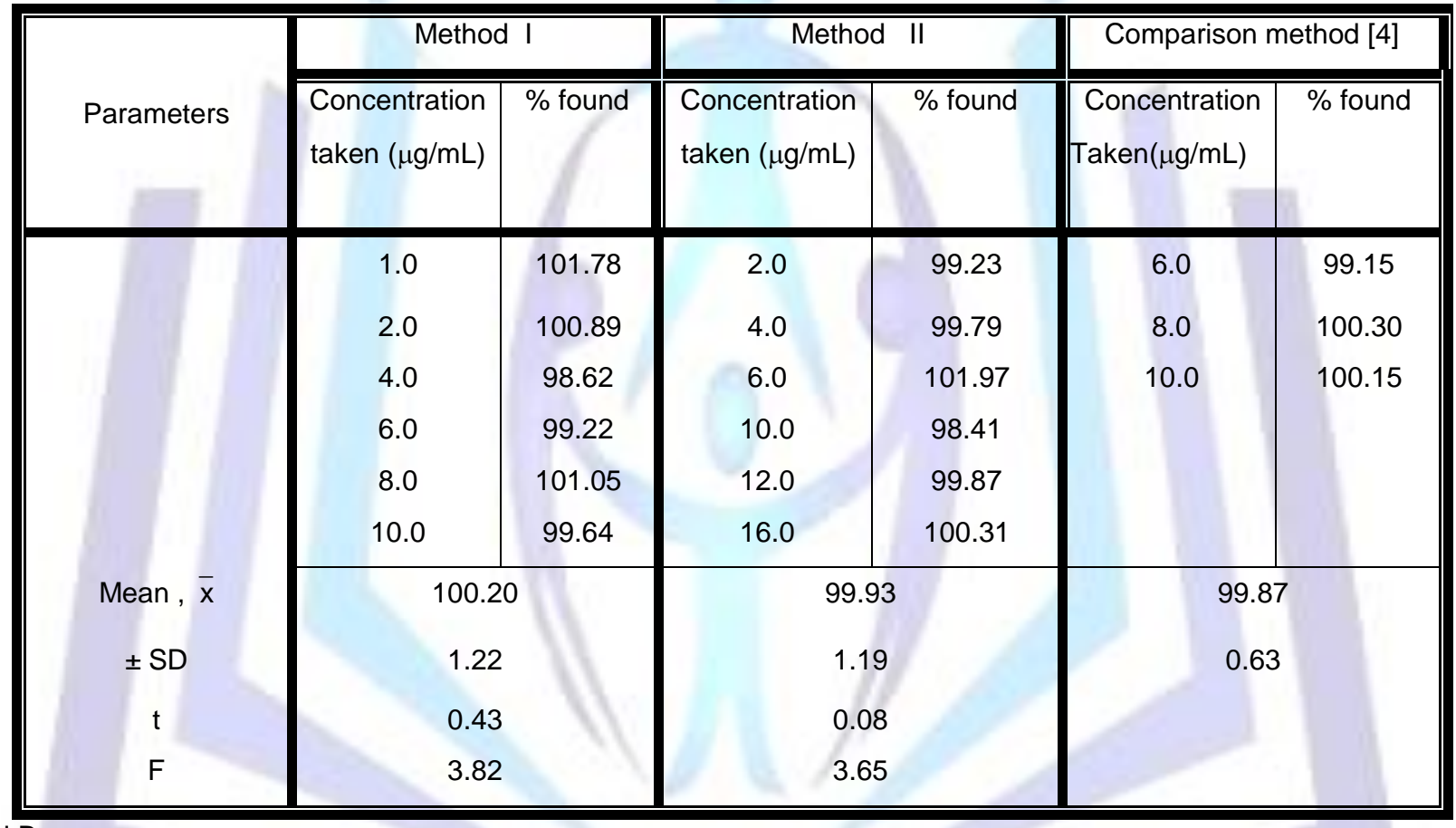

N.B.

Each result is the average of three separate determinations.

The tabulated $t$ and $F$ values are 2.36 and 19.30, respectively at $p=0.05$ [14]. 
Table (8): Precision data for the determination of the studied drugs by the proposed methods.

\begin{tabular}{|c|c|c|c|c|c|c|}
\hline \multirow[t]{2}{*}{ Parameters } & \multicolumn{3}{|c|}{$\begin{array}{l}\text { Intraday }^{\mathrm{a}} \\
\text { (Intermediate precision) }\end{array}$} & \multicolumn{3}{|l|}{$\begin{array}{l}\text { Interday }^{\text {b }} \\
\text { (Repeatability) }\end{array}$} \\
\hline & $\bar{x} \pm S . D$ & $\%$ RSD & \% Error & $\bar{x} \pm S . D$ & $\%$ RSD & $\%$ Error \\
\hline \multirow{3}{*}{$\begin{array}{l}\overline{\bar{g}} \\
\frac{\bar{t}}{\bar{t}} \\
\sum^{0}\end{array}$} & $99.90 \pm 0.62$ & 0.63 & 0.36 & $99.24 \pm 1.00$ & 1.01 & 0.58 \\
\hline & $99.18 \pm 0.93$ & 0.93 & 0.54 & $100.46 \pm 1.43$ & 1.42 & 0.82 \\
\hline & $100.53 \pm 0.83$ & 0.83 & 0.48 & $100.00 \pm 0.61$ & 0.61 & 0.35 \\
\hline \multirow{2}{*}{ 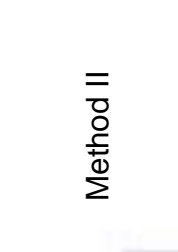 } & $100.37 \pm 1.32$ & 0.76 & 0.46 & $99.96 \pm 1.63$ & 1.63 & 0.94 \\
\hline & $99.73 \pm 0.61$ & 0.61 & 0.35 & $100.53 \pm 0.83$ & 0.83 & 0.48 \\
\hline
\end{tabular}

N. B.

Each result is the average of three separate determinations.

a on three successive occasion.

${ }^{\mathrm{b}}$ on three successive days.

Table (9): Application of the proposed methods to the determination of bumadizone in tablets.

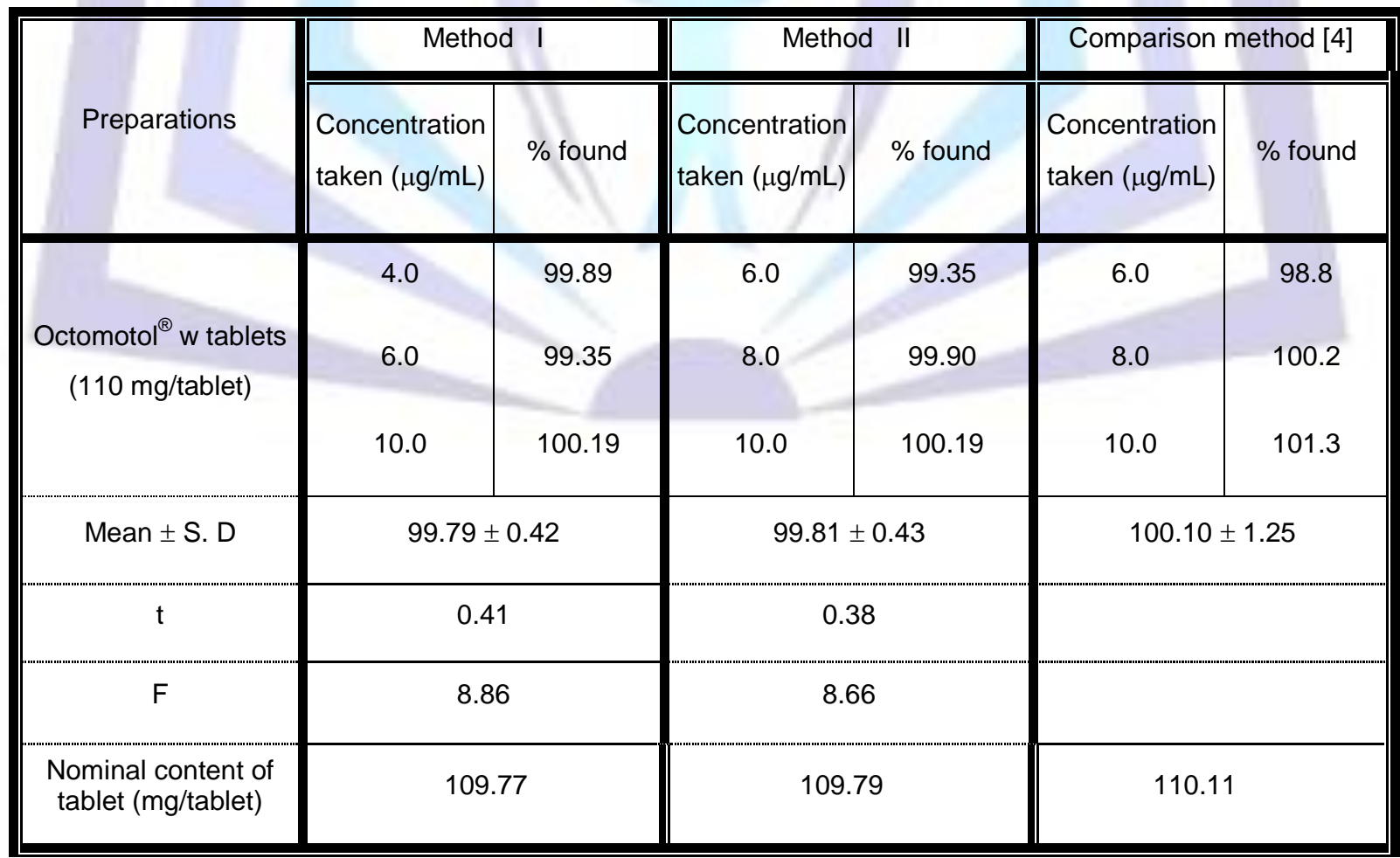

N.B.

Each result is the average of three separate determinations. 
The tabulated $t$ and $F$ values are 2.36 and 19.30, respectively at $p=0.05$ [14]

Octomotol W tablets (batch \# B1830212), labeled to contain $110 \mathrm{mg}$ of bumadizone calcium semi-hydrate, product of October Pharma S.A.E. Company, $6^{\text {th }}$ October City, Egypt.<smiles>CCCCC(C(=O)O)C(=O)N(Nc1ccccc1)c1ccccc1</smiles>

Fig. (1): Structure formula of bumadizone.

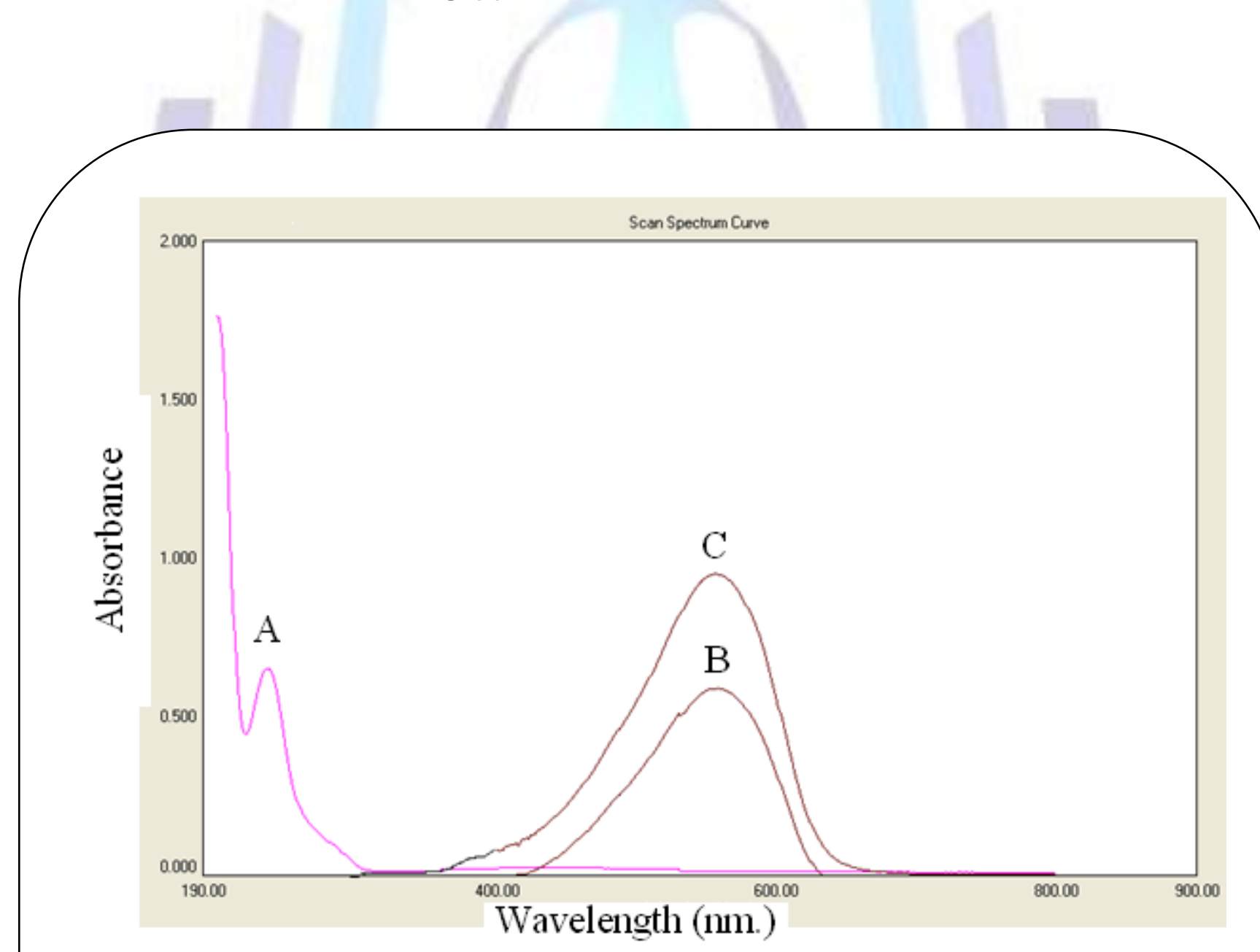

Fig. (2): Absorption spectra of:

(A) BUM $(10 \mu \mathrm{g} / \mathrm{mL})$ in water.

(B) The reaction product of BUM $(10 \mu \mathrm{g} / \mathrm{mL})$ with $\mathrm{MBTH}-\mathrm{Ce}(\mathrm{IV})$.

(C) The reaction product of BUM $(16 \mu \mathrm{g} / \mathrm{mL})$ with $\mathrm{MBTH}-\mathrm{FeCl}_{3}$. 


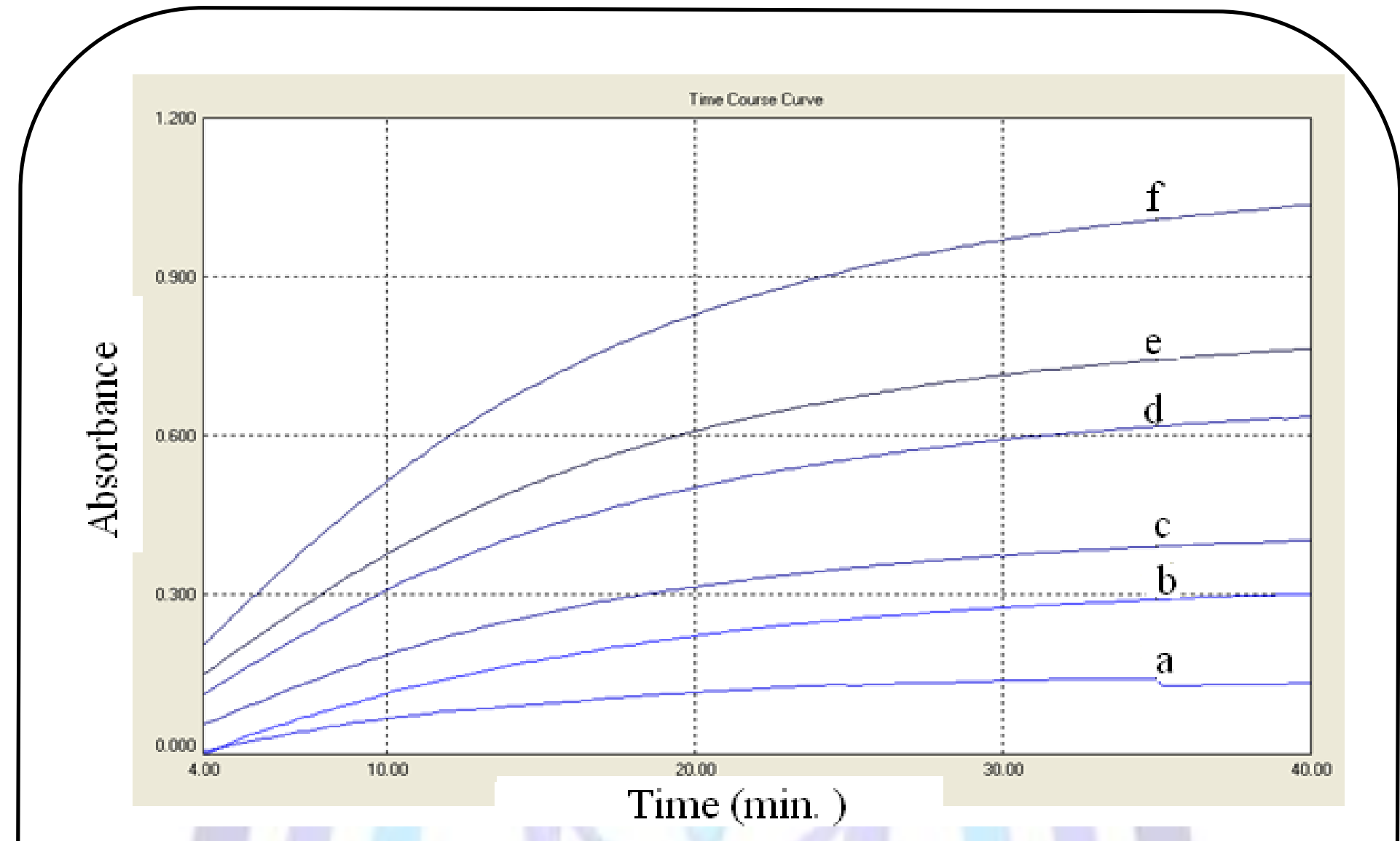

Fig. (3): Absorption versus time graphs for the oxidative coupling reaction between bumadizone and $\mathrm{MBTH} / \mathrm{FeCl}_{3}$ reagent (method II) :
a) $2 \mu \mathrm{g} / \mathrm{mL}$
b) $4 \mu \mathrm{g} / \mathrm{mL}$
c) $6 \mu \mathrm{g} / \mathrm{mL}$
d) $10 \mu \mathrm{g} / \mathrm{mL}$
e) $12 \mu \mathrm{g} / \mathrm{mL}$
f) $16 \mu \mathrm{g} / \mathrm{mL}$ 


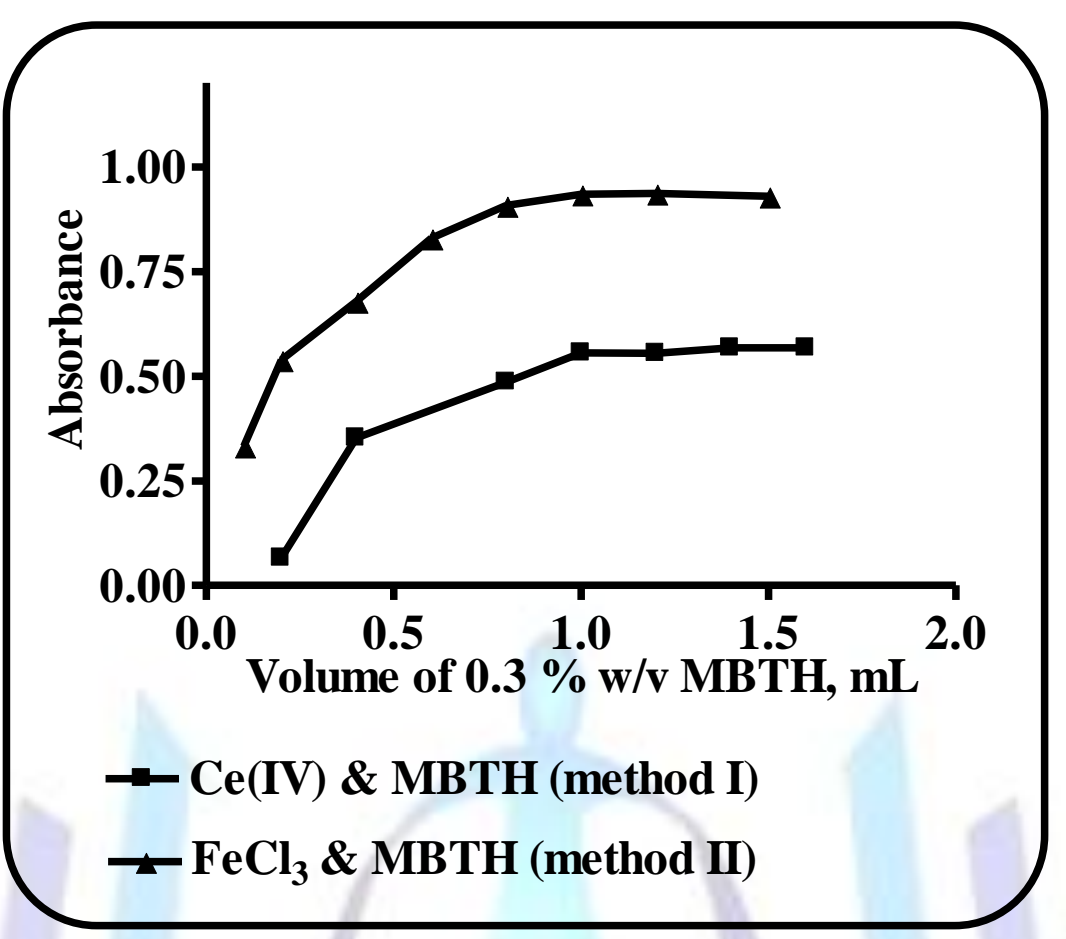

Fig. (4): Effect of volume of MBTH on absorbance values of the reactions products of : - BUM (10 $\mu \mathrm{g} / \mathrm{mL})$ with MBTH in presence of Ce(IV) (method I). - BUM $\left(16 \mu \mathrm{g} / \mathrm{mL}\right.$ ) with MBTH in presence of $\mathrm{FeCl}_{3}$ (method II).

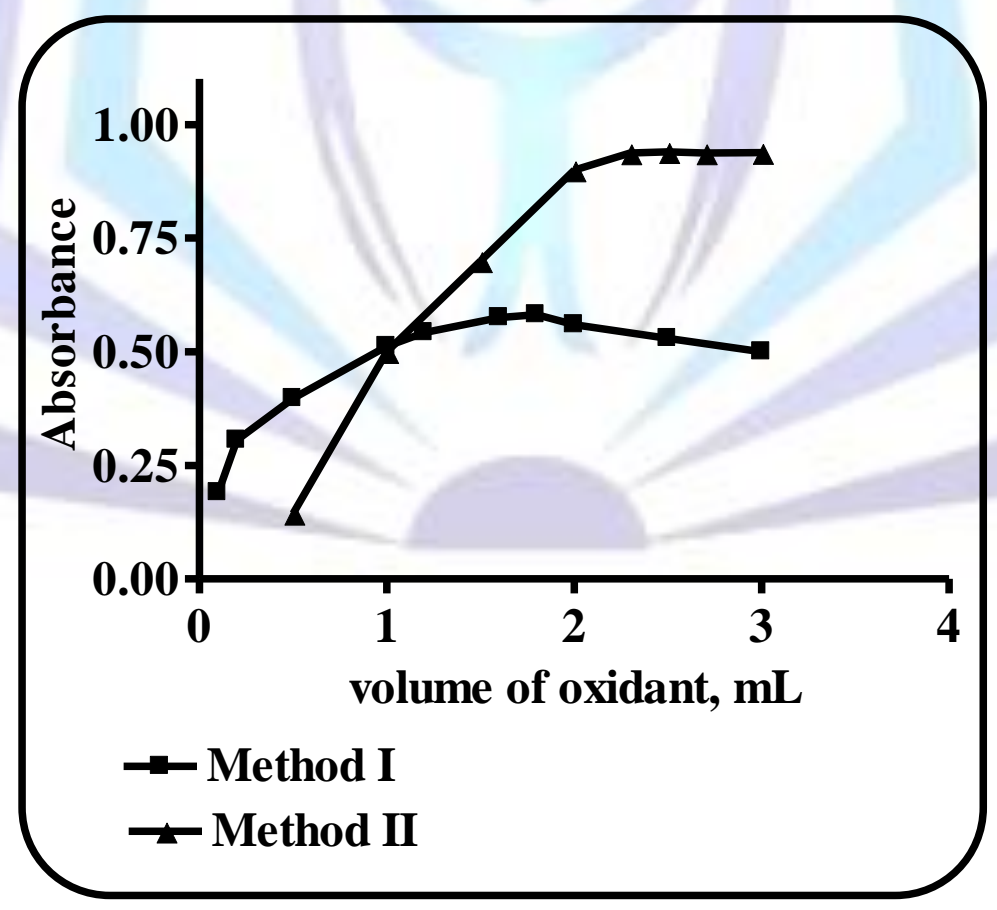

Fig. (5): Effect of volume of oxidant on absorbance values of the reactions products of : - BUM (10 $\mu \mathrm{g} / \mathrm{mL}$ ) with MBTH in presence of $0.5 \% \mathrm{w} / \mathrm{v} \mathrm{Ce}(\mathrm{IV})$ (method I). - BUM $(16 \mu \mathrm{g} / \mathrm{mL}$ ) with MBTH in presence of $0.5 \% \mathrm{w} / \mathrm{v} \mathrm{FeCl3} \mathrm{(method} \mathrm{II).}$ 
(A)

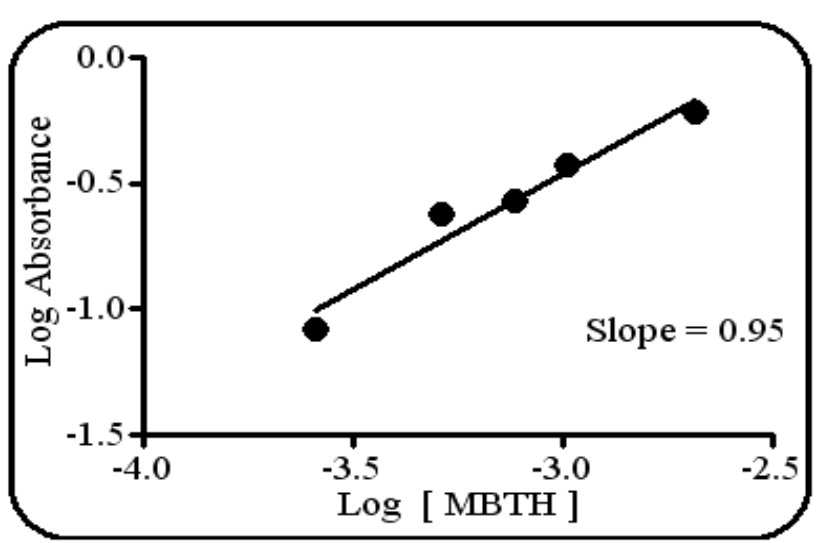

(B)

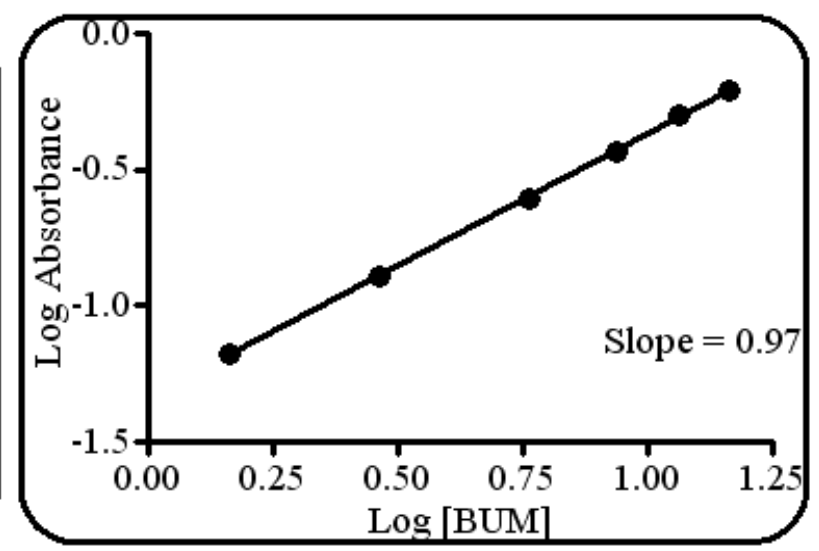

Fig. (6): Limiting logarithmic plots for the molar reactivity of BUM with MBTH in presence of Ce(IV) (method I).

(A) Log A vs $\log [\mathrm{MBTH}]$ when [BUM] kept constant.

(B) Log A vs log [BUM] when [MBTH] kept constant. 


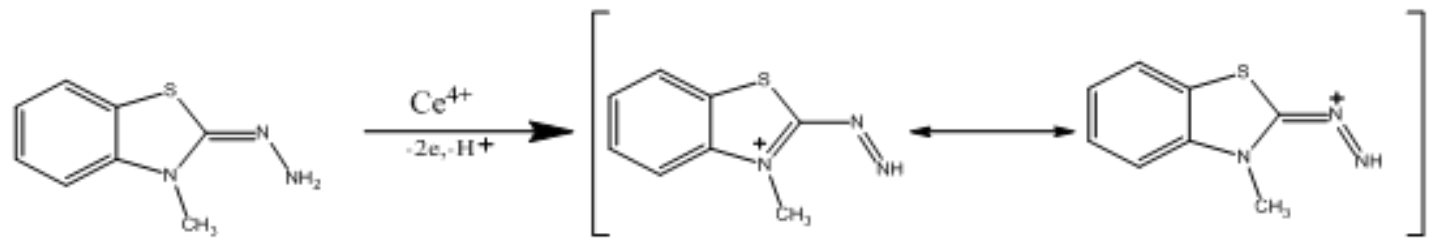

МВTH

Electrophilic Intermediate
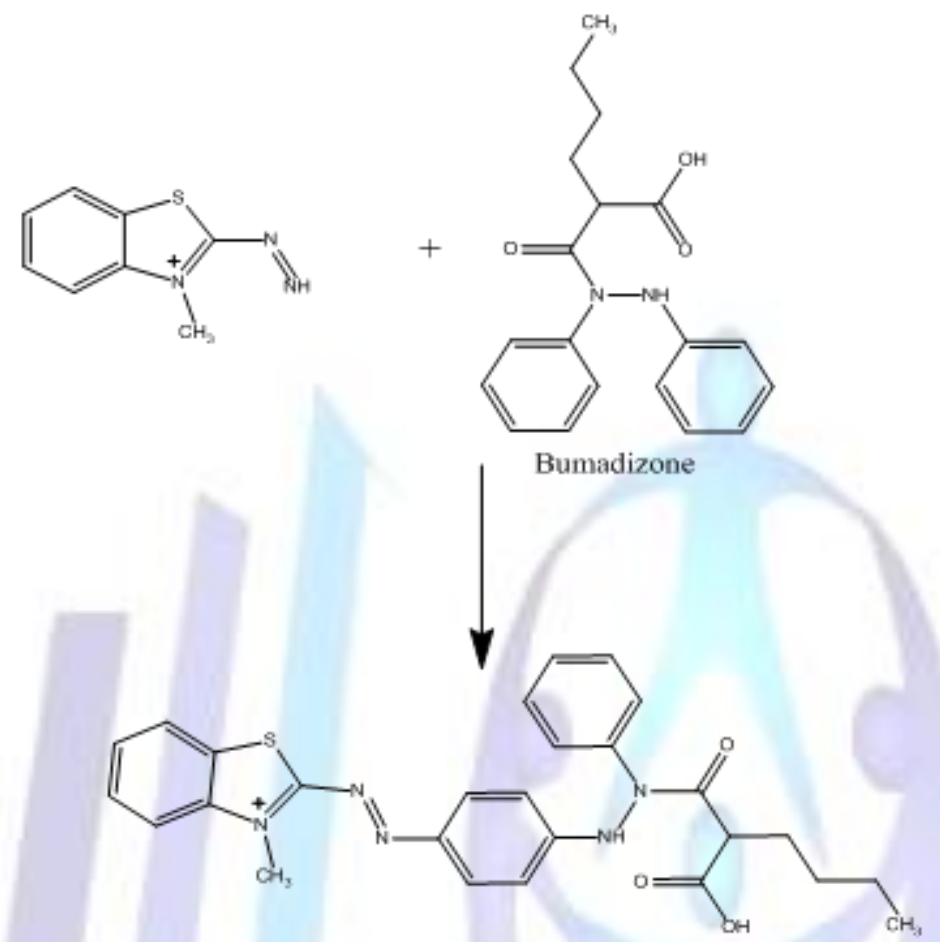

Red Colored Complex

Scheme1: The proposed reaction pathway of the oxidative coupling reaction of bumadizone and MBTH in the presence of $\mathrm{Ce}(\mathrm{IV})($ method I) as a model example.

\section{Reference:}

1) S.C. Sweetman, Martindale, The Complete Drug Reference, $37^{\text {th }}$ Ed., The Pharmaceutical Press, London, (2009) $p$. $(29,30)$.

2) H. Spahn, E. Mutschler, Arzneimittel-Forschung 31 (1981) 495-499.

3) I. Hermansson, J. Hermansson, Poster Presentation at the $13^{\text {th }}$ International Symposium on Column Liquid Chromatography, Stockholm (1989).

4) N. W. Ali, H. A. ZaaZaa, M. Abdelkawy, M. A. Magdy, Biomed. Chromatogr. 26 (2012) 1143-1149.

5) A. Epinosa-Mansilla, M. I. Acedo-Valenzulea, F. Salinas, F. Canda, Anal. Chim. Acta. (1998) 365-376.

6) A. A. El-Emam, F. F. Belal, M. A. Moustafa, S. M. El-Ashry, D. T. El-Sherbiny, S. H. Hansen, Farmaco 58 (2003) 1179-1186.

7) M. Rizk, N. El-Enany, F. F. Belal, J. AOAC. Int. 90 (2007) 679-685.

8) H. D. Revanasiddappa, B. Manjer, P. G. Ramoppa, Anal. Sci. 15 (1999) 661-664.

9) M. Rizk, F. F. Belal, F. Ibrahim, S. M. Ahmed, N. El-Enany, Sci. Pharm. 68 (2000) 173-188.

10) K. B. Yatsimirskii, Kinetic Methods of Analysis, Pergamon Press (1966), Oxford, UK.

11) H. A. Laitinan, \& W. E. Harris, Chemical Analysis, $2^{\text {nd }}$ Ed. (1975), McGraw-Hill, New York.

12) C. S. Sastry, P. Satyanarayana, M. K. Tummuru, Analyst 110 (1985) 189. 
13) ICH Harmonized Tripartite Guideline, Validation of analytical procedures: Text and Methodology, Q2(R1), Current Step 4 Version, Parent Guidelines on Methodology Dated November 6 1996, Incorporated in November 2005.http://www.bioforum.org.il/Uploads/Editor/karen/q2_r1_step4.pdf (accessed February15, 2010).

14) J. N. Miller, J. C. Miller, Statistics and chemometrics for Analytical Chemistry, $5^{\text {th }}$ Ed. Prentice Hall, England, (2005) p. 256.

15) J. Rose, Advanced Physico-Chemical experiments, Pitaman, London (1964) p. 67.

16) M. I. Walash, , M. Sharaf El-Din, M. S. Metwally, M. R. Shabana, J. Chin. Chem. Soc. 51 (2004) 523. 